\title{
Obesity and diabetes: interrelationship
}

\begin{abstract}
Diabetes epidemic can be attributed to the increasing incidence of obesity, especially in India. It is estimated that about $60-90 \%$ of all the patients with type 2 diabetes are obese $\left(\mathrm{BMI} \geq 30 \mathrm{~kg} / \mathrm{m}^{2}\right)$ or overweight $\left(\mathrm{BMI} \geq 25 \mathrm{~kg} / \mathrm{m}^{2}\right)$. A number of mechanisms involved in the pathogenesis of obesity have been proposed which play an important role in the development of diabetes by causing insulin resistance or hypersecretion of insulin. Excessive storage of fat in obese people leads to the release of excessive fatty acids resulting in insulin resistance and hyperglycemia. Insulin resistance is also a consequence of elevated secretion of cytokines (TNF- $\alpha$, IL- 6 , complement C3, MIF and leptin) by the adipose tissue resulting in the development of diabetes. There is a close association of diabetes and obesity with low plasma concentrations of adiponectin however, further experimental studies are required to establish the role of adiponectin. Development of both the diseases can be prevented to a large extent by increasing physical activities and maintaining a healthy weight. We undertook this review to study the interrelationship between diabetes and obesity.
\end{abstract}

Volume 8 Issue 2 - 2018

\author{
Samreen Siddiqui \\ Independent researcher, India
}

Correspondence: Samreen Siddiqui, Independent researcher, M-30I Taj Enclave, Geeta Colony, Link Road, Delhi- I I003I, India, Tel 9582865898

Email sid.samreen@gmail.com

Received: February 28, 2018 | Published: April 26, 2018

Keywords: obesity, type 2 diabetes, adipokines, cytokines

\section{Introduction}

Diabetes is one of the major health problems affecting large number of individuals and has reached epidemic proportion worldwide. The World Health Organization (WHO) has projected that around 300 million people will suffer from diabetes by $2025 .{ }^{1}$ Among the well-known risk factors of diabetes one of the most important and major risk factor is obesity $\left(\mathrm{BMI} \geq 30 \mathrm{~kg} / \mathrm{m}^{2}\right),{ }^{2}$ whose prevalence is also rising at a higher rate in developing countries, including India., Around $60-90 \%$ of all patients with type 2 diabetes are obese. ${ }^{5,6}$ The increasing incidence of diabetes can thus be attributed to the global epidemic of obesity. ${ }^{7}$ A number of clinical studies have reported an association between obesity and insulin resistance in adults as well as children ${ }^{8-10}$ and reports are also present which suggest that weight loss is associated with a decrease in insulin concentration and an increase in insulin sensitivity in adults and adolescents. ${ }^{11,12}$ This comorbid condition of obesity in patients with type 2 diabetes is very common and is often termed as "Diabesity". ${ }^{13,14}$ Sedentary lifestyle and changing food habits could be the main reasons for continuously increasing incidence of obesity and diabetes both in the urban as well as the rural areas in India. The rising prevalence of these two diseases is of concern as they may act as major risk factors for other fatal conditions like coronary artery disease (CAD). The aim of this review article was to study the relationship between obesity and diabetes. This is a general review and we reviewed fifty research papers before writing this paper.

\section{Pathophysiology of obesity and type 2 diabetes}

Pathogenesis of obesity appears to play a central role in the dysregulation of cellular mechanism that accounts for insulin resistance, which is the state of reduced responsiveness of liver, muscle and adipose tissue to insulin in type 2 diabetes. The stored fat is required for survival during nutritionally deprived states, however during state of prolonged abundance of food, excessive fat storage results in obesity. ${ }^{15,16}$ This excessive storage of fat that creates obesity eventually leads to the release of elevated levels of fatty acids (FFAs) from enhanced lipolysis. The release of these FFAs then induces lipotoxicity, as lipids and their metabolites create oxidant stress to the endoplasmic reticulum and mitochondria. This affects adipose as well as non-adipose tissues resulting in insulin-receptor dysfunction. The consequence is an insulin-resistant state which then creates hyperglycemia with compensated hepatic gluconeogenesis. ${ }^{17-19}$ Insulin resistance is a key factor for type 2 diabetes. FFAs also decrease utilization of insulin-stimulated muscle glucose, contributing further to hyperglycemia. Lipotoxicity from excessive FFAs also decreases secretion of pancreatic $\beta$-cell insulin, which eventually results in $\beta$-cell exhaustion (Figure 1). Moreover, excess adipocytes release inflammatory adipokines (TNF- $\alpha$, IL- 6 , complement $\mathrm{C} 3$, leptin and MIF), which, along with free fatty acids, provide the pathophysiologic basis for comorbid conditions associated with obesity such as insulin resistance and type 2 diabetes. Along with fatty-acid lipotoxicity, visceral adipokines also contribute to the adipokine inflammatory injury that leads to pancreatic $\beta$-cell dysfunction, which, in turn, decreases insulin synthesis and secretion. ${ }^{20,21}$ Adipocytes also stimulate fat-associated macrophages that also secrete monocyte chemoattractant protein 1 (MCP-1), macrophage migration inhibiting factor (MMIF), and resistin, all of which decrease insulin sensitivity (Figure 2) (i.e. enhance insulin resistance). ${ }^{22,23}$

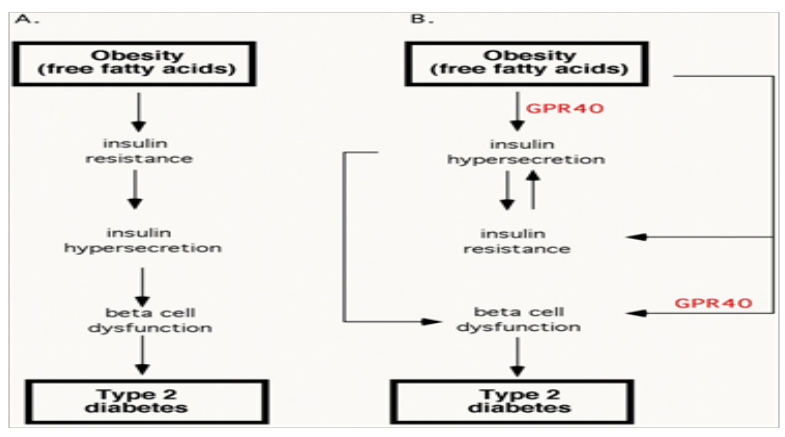

Figure I Pathway showing development of diabetes due to obesity. 


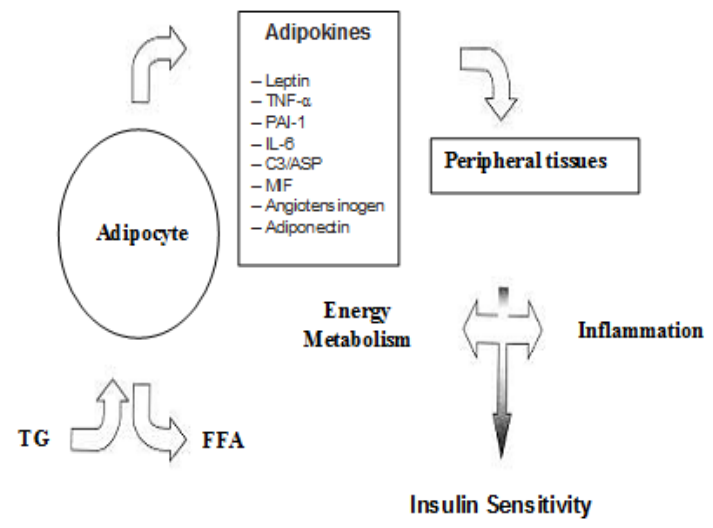

Figure 2 Adipokines regulating insulin sensitivity

\section{Obesity and diabetes interlinked}

A strong relationship between obesity and the onset of diabetes has been reported in a number of studies. Research has shown that people carrying more weight particularly around the tummy are more insulin ${ }^{24-27}$ resistant and may struggle to achieve good diabetes control. ${ }^{10,28,29}$ A number of mechanisms have been proposed to link obesity and insulin resistance which predispose to diabetes and includes increased production of adipokines or cytokines including tumor necrosis factor- $\alpha$, resistin and retinol-binding protein $4 .{ }^{30}$ Excess body fat and particularly visceral fat release increased amounts of FFAs in the blood. Elevation of FFAs levels directly affects insulin signaling and causes the liver and skeletal muscles to shift towards greater oxidation of FFAs for energy production and a relative inhibition of enzymes in the glycolytic cascades. As a result the capacity of liver and skeletal muscles cells to absorb and metabolize glucose decreases. Also, the tissues capacity to store glucose as glycogen decreases and the cells accumulate more triglycerides instead of glycogen.

Further, in an Indian the body fat percentage is significantly higher than a western counterpart with similar BMI and blood glucose level. It has been hypothesized that excess body fat and low muscle mass may explain the high prevalence of hyperinsulinemia and the high risk of type-2 diabetes in Asian Indians. ${ }^{31}$ The risk of diabetes increases exponentially as BMI increases above about $25 \mathrm{~kg} / \mathrm{m}^{2}{ }^{32,33}$ In a large cross-sectional study in middle aged Indians, a BMI $>23$ was found to be associated with increased risk for type 2 diabetes. ${ }^{34}$ Visceral fat increases the risk of diabetes by favouring insulin resistance. Patients with diabetes are usually advised to increase their physical activity and reduce weight. Prolonged duration of obesity also have deleterious effects on glucose homeostasis like increased resistance to glucose disposal and decreased secretion of insulin. Resistance to glucose disposal is strongly associated with obesity and results in high fasting and postload serum insulin concentrations. Prolonged duration of obesity could conceivably worsen this resistance..$^{35}$ Although excess fat in any region of the body is associated with increased risk of type 2 diabetes, it is generally held that an accumulation of abdominal fat ('central' obesity), as indicated by an increased waist: hip ratio is an independent risk for type 2 diabetes irrespective of the extent of obesity. ${ }^{36,37}$ This is mainly attributed to increased intra-abdominal (visceral) adiposity. Excessive deposition of lipid in muscle and liver also enhances the risk of type 2 diabetes through mechanisms of intracellular lipotoxicity.

\section{Genetic factors linking obesity and diabetes}

Obesity as well as diabetes, both are the examples of multifactorial diseases that arise through the interaction of multiple genetic and environmental factors. There has been evidences present which establish the genetic link between obesity and diabetes. Genomewide association scans (GWAS) and candidate gene approaches have identified 40 genes associated with type 2 diabetes and a similar number, although largely different, with obesity. Most type 2 diabetes genes appear to be related to b-cell dysfunction, with many fewer involved in pathways related to insulin resistance independent of obesity. ${ }^{38-41}$ A growing understanding of genetics and cellular function of the b-cell can identify potential mediators predisposing obese individuals to type 2 diabetes and further may provide insights for the development of new therapeutic agents. Although numerous diabetes and obesity associated genes have been identified, the known genes are estimated to predict only $15 \%$ of type 2 diabetes and $5 \%$ of obesity risk. ${ }^{42,43}$ Recent genome-wide studies have shown multiple loci on chromosomes which affect the obesity-related phenotypes. ${ }^{44}$ It can be speculated that the susceptibility to type 2 diabetes and obesity might also partly be due to shared genes. By comparing all of the published genome scans for type 2 diabetes and obesity, five overlapping chromosomal regions for both diseases have been identified and by analysing these five susceptibility loci for type 2 diabetes and obesity, 27 functional candidate genes have been pinpointed that are involved in eating behaviour, metabolism and inflammation. These genes might reveal a molecular link between the two disorders. ${ }^{45}$ By comparing the defined obesity-relevant pathways and Non-insulin dependent diabetes mellitus (NIDDM)- relevant pathways, it has been found that obesity-relevant pathways contains a gene set related to the insulin receptor, and coincidentally, there is a NIDDM-relevant gene set containing genes 2-fold up-regulated by insulin. Other than that, all relevant pathways in obesity and NIDDM are literally different. ${ }^{46}$

\section{Co-relation of adiponectin, obesity and diabetes}

Adiponectin is a novel fat protein secreted by adipose tissue and abundantly present in the circulation in humans. It has been hypothesized that this protein has a role in the pathogenesis of obesity and type 2 diabetes and that lower plasma levels of adiponectin are predictive of type 2 diabetes and found in patients with diabetes as well as in obese people. ${ }^{29,47-49}$ A review done by Hussain et al. ${ }^{50}$ has reported that concentrations of adiponectin may be down regulated by weight gain. Diabetes and obesity both are associated with low plasma adiponectin concentrations and hypoadiponectinemia in obese people is in large part attributable to insulin resistance.$^{51}$ A previous study in Japanese individuals have shown that the plasma adiponectin concentration is negatively correlated with body mass index (BMI) and therefore found to be lower in obese than in lean subjects, ${ }^{52}$ which is also the case in Indian population. ${ }^{53}$ However, the mechanism behind this close association between plasma concentration of adiponectin and insulin sensitivity is still unknown. Further experimental studies are required to study the molecular link between plasma levels of adiponectin and the pathogenesis of obesity and diabetes. 


\section{Conclusion}

Obesity and diabetes which have become major health problems in India as well as globally are closely linked together, obesity serves as a major risk factor for type 2 diabetes and weight gain management can reduce the risk of diabetes to a larger extent. Urbanization, changing life style \& food habits are the main reasons for increasing obesity in India and consequently responsible for increasing incidence if diabetes. Increasing physical exercise and maintaining ideal weight can lower the chances of developing diabetes. Further, reducing FFAs levels should be an important goal in the management of patients with type 2 diabetes mellitus. Preventing obesity $\left(\mathrm{BMI} \geq 30 \mathrm{~kg} / \mathrm{m}^{2}\right)$ could largely prevent diabetes. More large-scale clinical studies are required to understand the molecular mechanisms behind obesity causing insulin-resistance and the genetic relationship between both the diseases in order to develop better therapeutic remedies.

\section{Acknowledgements}

None.

\section{Conflict of interest}

The authors declare there is no conflict of interest.

\section{References}

1. Raval A, Dhanaraj E, Bhansali A, et al. Prevalence \& determinants of depression in type 2 diabetes patients in a tertiary care centre. Indian J Med Res. 2010;132:195-200.

2. American Diabetes Association. Diagnosis and Classification of Diabetes Mellitus, American Diabetes Association. Diabetes Care. 2010;33(Suppl 1):S62-S69.

3. Misra A, Pandey RM, Devi J R, et al. High prevalence of diabetes, obesity and dyslipidemia in urban slum population in northern India. Int obes Relat Metab Disord. 2001;25:1722-1729.

4. Mishra A. Khurana L. obesity and metabolic syndrome in developing countries. J Clin Endocriol Metab. 2008;93:59-30.

5. Halpern A, Mancini MC. Diabesity: are weight loss medications effective? Treat Endocrinol. 2005;4:65-74.

6. Stumvoll M, Goldstein BJ, van Haeften TW. Type 2 diabetes: principles of pathogenesis and therapy. Lancet. 2005;365:1333-1346.

7. Eckel RH, Kahn SE, Ferrannini E, et al. Obesity and Type 2 Diabetes: What Can Be Unified and What Needs to Be Individualized? Diabetes Care. 2011;34:1424-1430.

8. St- Pierre J, Lemieux I, Vohl MC, et al. Contribution of abdominal obesity and hyper-triglyceridesmia to impaired fasting glucose and coronary artery disease. A J Cardiol. 2002;90:15-18.

9. Tataranni PA. Pathophysiology of obesity-induced insulin resistance and type 2 diabetes mellitus. Eur Rev Med Pharmacol Sci. 2002;6:2732 .

10. Pratley RE, Weyer C, Bogardus C. Metabolic abnormalities in the development of noninsulin-dependent diabetes mellitus. In: LeRoith D, Taylor SI, et al. editors. Diabetes mellitus. Philadelphia: LippincotRaven Publishers;2000:548-557.

11. Adams TD, Gress RE, Smith SC, et al. Long-term mortality after gastric bypass surgery. Engl J Med. 2007;357:753-761.

12. Buchwald H, Estok R, Fahrbach K, et al. Weight and type 2 diabetes after bariatric surgery: systematic review and metaanalysis. Am J Med. 2009;122:248-256.
13. Kalra S, Unnikrishnan AG. Obesity in India: The weight of the nation. J Med Nutr Nutraceut. 2012;1:37-41.

14. Yajnik CS, Ganpule-Rao AV. The obesity-diabetes association: What is different in Indians? Int J Low Extrem Wounds. 2010;9:113-115.

15. Seeley RJ, Woods SC. Monitoring of stored and available fuel by the CNS: Implications for obesity. Nat Rev Neurosci. 2003;4:901-909.

16. Spiegelman BM, Flier JS. Obesity and the regulation of energy balance. Cell. 2001;104:531-543.

17. Evans RM, Barish GD, Wang YX. PPARs and the complex journey to obesity. Nat Med. 2004;10:355-361.

18. Hutley L, Prins JB. Fat as an endocrine organ: relationship to the metabolic syndrome. Am J Med Sci. 2005;330(6):280-289.

19. Hussain A, Hydrie MZI, Claussen B, et al. Type 2 Diabetes and obesity: A review. Journal of Diabetology. 2010;1(2):4.

20. Redinger RN. The Pathophysiology of Obesity and Its Clinical Manifestations. Gastroenterol Hepat. 2007;3(11):856-63.

21. Straczkowski M, Kowalska I, Stepien A, et al. Increased plasmasoluble tumor necrosis factor alpha receptor 2 level in lean nondiabetic offspring of type 2 diabetic subjects. Diabetes Care. 2002;25(10):1824-1828.

22. Wellen KE, Hotamisligil GS. Inflammation, stress, and diabetes. $J$ Clin Invest. 2005;115:1111-1119.

23. Verma $\mathrm{S}$, Li SH, Wang $\mathrm{CH}$, et al. Resistin promotes endothelial cell activation: further evidence of adipokine-endothelial interaction. Circulation. 2003;108(6):736-740.

24. Meigs JB, Wilson PW, Fox CS, et al. Body mass index, metabolic syndrome, and risk of type 2 diabetes or cardiovascular disease. $J$ Clin Endocrinol Metab. 2006;91(8):2906-2912.

25. Nagaya $\mathrm{T}$, Yoshida $\mathrm{H}$, Takahashi $\mathrm{H}$, et al. Increases in body mass index, even within non-obese levels, raise the risk for Type 2 diabetes mellitus: a follow-up study in a Japanese population. Diabet Med. 2005;22(8):1107-1111.

26. Oguma Y, Sesso HD, Paffenbarger RS, et al. Weight change and risk of developing type 2 diabetes. Obes Res. 2005;13(5):945-951.

27. Wannamethee SG, Shaper AG, Walker M. Overweight and obesity and weight change in middle aged men: impact on cardiovascular disease and diabetes. J Epidemiol Community Health. 2005;59(2):134-139.

28. de Ferranti S, Mozaffarian D. The perfect storm: obesity, adipocyte dysfunction, and metabolic consequences. Clin Chem. 2008;54(6):945-955.

29. Weyer C, Funahashi T, Tanaka S, et al. Hypoadiponectinemia in Obesity and Type 2 Diabetes: Close Association with Insulin Resistance and Hyperinsulinemia. $J$ Clin Endocrinol Metab. 2001;86(5):1930-1935.

30. Deng Y, Scherer PE. Adipokines as novel biomarkers and regulators of the metabolic syndrome. Ann N Y Acad Sci. 2010;1212:E1-E19.

31. Pandya H, Lakhani JD, Patel N. Obesity is becoming synonym for diabetes in rural areas of India also - an alarming Situation. Int J Biol Med Res. 2011;2(2):556-560.

32. Chan JM, Stampfer MJ, Ribb EB, et al. Obesity, fat distribution and weight gain as risk factors for clinical diabetes in man. Diabetes Care. 1994;17(9):961-969.

33. Colditz GA, Willett WC, Rotnitzky A, et al. Weight gain as a risk factor for clinical diabetes mellitus in women. Ann Intern Med. 1995;122(7):481-486. 
34. Snehalatha C, Vishwanathan V, Ramachandran A. Cutoff values for normal anthropometric variables in Asian Indian adults. Diab Care. 2003;26(5):1380-1384.

35. Everhart JE, Pettitt DJ, Bennett PH, et al. Duration of Obesity Increases the Incidence of NIDDM. Diabetes. 1992;41(2):235-240.

36. The Emerging Risk Factor Collaboration. Separate and combined associations of body-mass index and abdominal adiposity with cardiovascular disease: collaborative analysis of 58 prospective studies. Lancet. 2011;377(9771):1085-1095.

37. Montague CT, O' Rahilly S. The perils of portliness: causes and consequences of visceral adiposity. Diabetes. 2000;49(6):883-888.

38. Rampersaud E, Damcott CM, Fu M, et al. Identification of novel candidate genes for type 2 diabetes from a genome-wide association scan in the Old Order Amish: evidence for replication from diabetesrelated quantitative traits and from independent populations. Diabetes. 2007;56(12):3053-3062.

39. Hayes MG, Pluzhnikov A, Miyake K, et al. Identification of type 2 diabetes genes in Mexican Americans through genomewide association studies. Diabetes. 2007;56:3033-3044.

40. Scherag A, Dina C, Hinney A, et al. Two new loci for body-weight regulation identified in a joint analysis of genome-wide association studies for early-onset extreme obesity in French and German study groups. PLoS Genet. 2010;6(4):e1000916.

41. Lindgren CM, Heid IM, Randall JC, et al. Genome-wide association scan meta-analysis identifies three loci influencing adiposity and fat distribution. PLoS Genet. 2009;5(7):1.

42. Bogardus C. Missing heritability and GWAS utility. Obesity (Silver Spring). 2009;17(2):209-210.

43. Lander ES. Initial impact of the sequencing of the human genome. Nature. 2011;470(7333):187-197.
44. Loos RJ, Bouchard C. Obesity-is it a genetic disorder? J Int Med. $2003 ; 254: 401-425$

45. Elbers CC, Onland-Moret NC, Franke L, et al. A strategy to search for common obesity and type 2 diabetes genes. Trends Endocrinol Metab. 2007;18(1):19-26.

46. HU H, LI X. Networking pathways unveils association between obesity and non-insulin dependent diabetes mellitus. Pac Symp Biocomput. 2008;13:255-266.

47. Statnick MA, Beavers LS, Conner LJ, et al. Decreased expression of apM1 in omental and subcutaneous adipose tissue of humans with type 2 diabetes. International Journal of Reproduction and Diabetes Research. 2000;1(2):151-158.

48. Matsuzawa Y. The metabolic syndrome and adipocytokines. FEBS 2006;580(12):2917-2921.

49. Diez JJ, Iglesias P. The role of novel adipocyte-derived hormone adiponectin in human disease. Eur J Endocrinol. 2003;148(3):293300 .

50. Hussain A, Hydrie MZI, Claussen B, et al. Type 2 Diabetes and obesity: A review. Journal of Diabetology. 2010;2:1.

51. Ouchi N, Ohishi M, Kihara S, et al. Association of hypoadiponectinemia with impaired vasoreactivity. Hypertension. 2003;42(3):231-232.

52. Hotta K, Funahashi T, Arita Y, et al. Plasma concentrations of a novel, adipose-specific protein, adiponectin, in type 2 diabetic patients. Arterioscler Thromb Vasc Biol. 2000;20(6):1595-1599.

53. Mohan V, Deepa R, Pradeepa R, et al. Association of low adiponectin levels with the metabolic syndrome-the Chennai Urban Rural Epidemiology Study (CURES-4). Metabolism. 2005;54(4):476-481. 